\title{
DISCURSO HISTÓRICO Y CARNAVALIZACIÓN DE LA HISTORIA: "EL JURAMENTO" DE RENÉ MARQUÉS
}

\author{
POR \\ MARÍA M. CABALLERO WANGÜEMERT \\ Universidad de Sevilla
}

Serescritores emprenderuna agónica e inacabable búsqueda de la verdad.

René Marqués, La función del escritor puertorriqueño.

La novela puertorriqueña se ha puesto al día con el mundo y ha entrado de lleno en el llamado boom de la novelística latinoamericana con obras como $\mathrm{El}$ francotirador de Pedro Juan Soto, Figuraciones en el mes de Marzo de Emilio Díaz Valcárcel y La guaracha del macho Camacho de Luis Rafael Sánchez. ${ }^{1}$

Este juicio de José Luis González sobre alguno de sus compañeros de generación es igualmente válido para su propia obra y puede servir como marco introductorio a la de René Marqués, considerado guía y mentor de esta "generación del cincuenta". ${ }^{2}$ Me propongo comprobar la validez de este aserto a través del estudio de "El juramento", ${ }^{3}$ uno de sus cuentos más largos, "cuyos elementos tragicómicos lo diferencian mucho de todas las demás obras narrativas del autor". ${ }^{4}$ En efecto, no es habitual que el puertorriqueño opte por la distorsión

\footnotetext{
${ }^{1}$ Nora G. Orthmann y Caridad L. Silva de Velázquez, "José Luis González: observaciones sobre su obra y su generacion". Sin Nombre 2 (jul-sept, 1979) 34.

${ }^{2} \mathrm{Si}$ nos atenemos a las fechas de publicación tendría que ser denominada así, a pesar de que una parte de la crítica habla de generación del cuarenta por la importancia de esta década en su formacion. Betty Rita Gomez Lance, ¿Existe una "promoción del cuarenta" en el cuento puertorriqueño? Revista Iberoamericana 63 (Pittsburgh, jul-dic, 1964) 283292; Seymour Menton, "La generación puertorriqueña del cuarenta". Hispania 44 (May, 1961) 209-211. En el artículo citado, José Luis González se proclama integrante de la "generación del cincuenta", señalando escritores diversos a este grupo para el cuarenta. 3 "Eljuramento", incluido en la primera colección de relatos marquesianos: Otro día nuestro (San Juan de Puerto Rico: Imp. Venezuela, 1955). Será recogido posteriormente en la tercera edición de En una ciudad llamada San Juan, segunda de sus colecciones (México: UNAM, 1960). Aquí seguiré el texto difundido en Europa por Cahiers du Monde Hispanique et Luzo-Brézilien (Caravelle) 18, en un número monográfico dedicado al cuento puertorriqueño (Toulouse, 1972) 93-109.

4 Vernon L. Peterson, Idea y representación literaria en la narrativa de René Marqués (Madrid: Pliegos, 1986) 143.
} 
humorística como sucede aquí; en ocasiones sus textos tienden hacia un patetismo que desvirtúa su eficacia. Por el contrario, "El juramento", escrito en la primera mitad de la década del cincuenta, se destaca por su modernidad técnica y una aparente asepsia, fruto de la distancia focal que establece el narrador y el matiz irónico de la historia.

\section{EL SALTO A LA MODERNIDAD: LOS DESPLAZAMIENTOS TEMPORALES}

Lo primero que percibe el lector es su modernidad técnica. El narrador reconstruye la vida del anónimo protagonista cifrándola en los momentos decisivos mediante la sistemática manipulación del tiempo. Logrará así dilatar la brevísima duración de la historia - los escasos minutos del final de un juiciocon el panorama de toda una existencia sin sentido culminada en una condena incomprensible y absurda. Psicológicamente el relatoes perfecto: la modernidad técnica, lejos de ser gratuito artificio experimental, está al servicio de la verosimilitud; el personaje debe repasar los episodios clave en busca de una respuesta que se presenta como apremiante. Y lo hará recurriendo a una paródica "maquinita del tiempo", artilugio moderno que recuerda la máquina fijadora de figuras en La invención de Morel de Bioy Casares. Como en aquélla, la escena queda a disposición del usufructuario, en este caso víctimainvoluntaria de esa tiránica búsqueda a través del recuerdo:

\footnotetext{
¿Movería la maquinita del tiempo de adelante hacia atrás, o a la inversa? (...) Pacientemente la maquinita seguía avanzando. Un año de vida. Nada. Tres años. Nada. Seis años. Nada. Siete años. La maquinita empezo a dar tropezones angustiosos. Ocho años. La maquinita se par6 (...)

Trat6 entonces, con mucho disimulo, de empujar la maquinita, a ver si seguía caminando. La maquinita se quedó quieta. Olvidando toda prudencia le dio tremendo golpe. La maquinita siguió tan inmovil e impasible como si no la hubiesen tocado (...) Y comprendió que no habfa escape. Tenía que examinar el año octavo. ¿Por qué ése? No había por qué. S6́lo un imperioso mandato de acercarse a $\mathrm{el}^{.5}$
}

En el pasado estará la clave condenatoria del acusado. Por ello sóloel marco temporal -la primera y última páginas corresponden al relato primero: el instante final del juicio. A partir de aquílos reiterados flashback siguen un proceso de retroversión cronológica. Su punto de partida es un tiempo próximo, ocupado por los sucesos del juicio, que a su vez se constituye en relato-base de los restantes fragmentos analépticos. ${ }^{6}$ Estos úl timos comprenden: untiemporemoto, indeterminado, que se pone en marcha con el arresto del protagonista:

\footnotetext{
5 René Marqués, "El juramento ...”. Cahiers, 103.

- Seguiré la terminología de Gérard Genette en "Discours du récit". Figures III (Paris, Seuil, 1972) 67-173.
} 
La 'vaina', como diría el hombre del martillito, había empezado muchos meses atrás. Empezo exactamente aquella madrugada cuando lo sacaron de la cama para arrestarlo. Meche lo miro con ojos de espanto, pero él le dijo que sin duda debía ser una equivocación y que volvería enseguida. ${ }^{7}$

-varios fragmentos temporales indeterminados que se remontan al nacimiento del protagonista y se relacionan con hechos acumulados por el fiscal como pruebas condenatorias. Por su extensión y funcionalidad se destaca un episodio de la niñez: el primer día en la escuela de Arecibo y el subsiguiente choque con la educación americana. Alternará contrapuntisticamente durante algunas páginas con el tiempo del juicio.

Esquemáticamente el proceso temporal quedaría asf:

\begin{tabular}{|c|c|c|c|c|}
\hline & & & & \\
\hline $\begin{array}{l}\text { relato } \\
\text { primero }\end{array}$ & $\begin{array}{l}\text { sucesos } \\
\text { indeterm. = } \\
\text { analepsis } \\
\text { (tiempo } \\
\text { remoto) }\end{array}$ & $\begin{array}{l}\text { arresto = } \\
\text { analepsis } \\
\text { (tiempo } \\
\text { remoto) }\end{array}$ & $\begin{array}{l}\text { jucio = } \\
\text { analepsis } \\
\text { (tiempo } \\
\text { próximo) }\end{array}$ & $\begin{array}{l}\text { relato } \\
\text { primero }\end{array}$ \\
\hline
\end{tabular}

Esa constante huida hacia atrás - que recuerda Viaje a la semilla, de Alejo Carpentier- tiene una funcionalidad apremiante: encontrar la "falta", simbólicamente representada por el juramento que da título al cuento. Absurdo, desconocido ... obligará al protagonista a revolver en los arcanos de la memoria hasta que "se haga la luz" en su desesperada búsqueda, al recordar el episodio de la escuela:

¡Juro por mi madre que no soy americano! ¡Y juro por Dios santo que nadie nunca me obligará a serlo! ${ }^{8}$

A partir de ahí el relato puede avanzar hacia adelante -a diferencia del texto del cubano- y culminar ante las puertas de la cárcel que sepultan al anónimo hombrecillo de 28 años .... El viaje al pasado ha concluido y el círculo se ha cerrado. No obstante, el panorama desplegado ante el lector no quiere ser exhaustivo, deja lagunas en la historia destinadas a motivarle. La mayoría de los fragmentos analépticos culminan en una elipsis implícita, en un vacio narrativo acorde con ese retorno del subconsciente y el recuerdo. En "El juramento" se pueden detectar hasta siete fragmentos de ese tipo. ${ }^{9}$ Muchos de ellos son sumarios eficaces en su misión de sintetizar una materia tan amplia. A veces se combinan con pasajes dialogados que remansan la duración, potenciando la garra dramática del texto. Los más interesantes están

\footnotetext{
${ }^{7}$ René Marqués, "El juramento ...”. Cahiers, 95.

${ }^{8}$ Cahiers, 108.

'René Marqués, “El juramento ...”. Cahiers , 94, 95, 97, 100, 103 y 104-108.
} 
encaminados a poner de manifiesto ante el lector el alto grado de corrupción que afecta a poderes administrativos y judiciales. La conversación mantenida por el detenido y su abogado, poco antes del juicio, es transparente al respecto:

-Me imagino que si no pudo conseguir la fianza, tampoco dispondrá de los medios para comprar al jurado.

-Ah, pero ¿se compra?

$\rightarrow$ Si, se compra. ¿Qué le pasa a Ud? Se compra un jurado con dinero, con regalos, con presión política, con amenazas de muerte. ¿Dispone Ud. de alguno de esos medios?. ${ }^{10}$

Frente al viejo realismo social, aquí la crítica es tanto más efectiva cuanto que el narrador se abstiene de opinar, limitándose a presentar escuetamente el funcionamiento que, por sí mismo, es insultante. El propio Marqués lo ha recogido en forma teórica:

El escritor se sitúa generalmente como observador objetivo, más allá del bien y del mal. Revela y denuncia pero se abstiene de juzgar personajes y situaciones dejando la responsabilidad del juicio definitivo en manos del lector. ${ }^{11}$

Si el tono de protesta y el compromiso explícito del escritor caracteriza las décadas del treinta al cincuenta el indigenismo de Icaza o la novela de la dictadura de Asturias - ahora "Ta sátira ha ido progresivamente reemplazando el compromiso en la nueva novela ...", 12 y el narrador tiene buen cuidado de mantener una aparente asepsia auto-excluyéndose del texto. Esa técnica triunfa ejemplarmente en los fragmentos dialogados. De cualquier forma, escena y sumarios se suceden en el relato dentro de una estructura singulativa que alterna con pasajes iterativos, ${ }^{13}$ destinados a condensar la rutina reiteradora de los hechos. A veces una pequeña escena singulativa ilustra ese desarrollo iterativo:

Recordaba que en varias ocasiones le había sido imposible contener la risa. Cierto que cada carcajada le costó una condena por desacato. Pero en aquellas ocasiones no había podido mantenerse serio (...).

La vez que rí mejor fue cuando ...14

${ }^{10}$ René Marqués, "El juramento". Cahiers, 98.

"Marqués, "El cuento puertorriqueño en la promoción del cuarenta". El puertorriqueño dócil y otros ensayos 1953-1971 (Río Piedras: Editorial Antillana, 1977) 96. Personalmente creo que "El juramento" es uno de los mejores relatos del puertorriqueño precisamente porque logra ceñirse a este presupuesto, cosa que no es tan habitual en ell).

12 Donald L. Shaw, Nueva narrativa hispanoamericana (Madrid: Cátedra, 1981) 220.

${ }^{13}$ Esquemáticamente el juego seria: singulativo: p. 93; iterativo pp. 94-95; singulativo pp. 97-109, con breves desarrollos iterativos.

14 René Marqués, "El juramento ...". Cahiers, 94. El subrayado que corresponde a la iteración es mío. 
Modernidad técnica, en resumen; juego narrativo perfectamente calculado para ampliar desde dentro el estrecho marco impuesto al relato por su brevedad y reflejar la inevitable interacción de presente y pasado que opera sobre el protagonista.

\section{PUERTO RICO: UNA CULTURA ASEDIADA}

"Puerto Rico no ha llegado a meta final alguna. Su destino político sin resolver sigue siendo hoy cáncer tan corrosivo en el cuerpo social como lo fuera en décadas anteriores" ${ }^{15}$ Estas palabras de Marqués sintetizan la obsesión que genera y justifica toda su obra literaria -ensayística, narrativa y dramáticatema que ya ha sido insistentemente abordado por la crítica. ${ }^{16}$ Me interesa ahora reseñar cómo la problemática derivada del peculiar E.L.A. y la subsiguiente "tansculturación e interferencia lingüística" - por decirlo con palabras de Germán Granda ${ }^{17}$ - se erigen en el verdadero motor interno de "El juramento". Todo el relato se construye bajo ese prisma, pero me gustaria detenerme en la eficacia de dos recursos de distinto nivel: la ausencia de libertad, puesta de manifiesto a través de la manipulación espacial; y el bloqueo educativo deducible de una escena que funciona como dato escondido en la línea de Hemingway o García Márquez. ${ }^{18}$

Si consideramos el primero - regido por el principio de economía propio de la narrativa contemporánea- observamos el predominio del espacio interior con un valor simbólico. Tanto la sala del juicio como la cárcel se convierten en

${ }^{18}$ Marqués, "Pesimismo literario y optimismo político: su coexistencia en el Puerto Rico actual". El puertorriqueño docil ...., Cahiers, 73.

${ }_{16}$ José Luis González, Literatura eidentidad nacional en PuertoRico. (RíoPiedras:Huracán, 1979); Manuel Maldonado Denis, Puerto Rico: una interpretacion histórico-social (México: Siglo XXI, 1964); Eduardo Seda Bonilla, Requiem por una cultura (Río Piedras: Bayoán, 1974); Carlos Varo, Puerto Rico: radiografia de un pueblo asediado (Río Piedras: Ediciones Puerto, 1973).

17 Germán Granda, Transculturación e interferencia lingulstica en el Puerto Rico contemporáneo (1898-1968) (Bogotá: Publicaciones del Instituto Caro y Cuervo, 1968). ${ }^{18}$ Por cierto que esta escena del primer día en la escuela de Arecibo volverá a aparecer en el capítulo XVIII de La vispera del hombre (México: Club del Libro de Puerto Rico, 1959), con idéntico planteamiento y exacto desenlace de rebeldía por parte del protagonista. Este procedimiento intertextual supone la reiteracion literal de textos propios transpuestos comocita oreminiscencias, y mediante isotoptas metafóricas o metonímicas. Nos hallamos ante el fruto de un deseo marquesiano: configurar todo un mundo definido por su ideario sociopolítico. Paralelamente -y como sucede por ejemplo con García Márquez- el público lector a su vez pone en marcha la intertextualidad, al reconocer en cada nueva produccínn del autor, temas precedentes. Véase María M. Caballero, "La intertextualidad bíblica en Otro día nuestro de René Marqués". Anuario de Estudios Americanos 37 (Sevilla, 1982) 527-638. 
marcos opresores destinados a reflejar la política de Puerto Rico. Según Marqués la celda en la que se recluye al protagonista antes de ser juzgado, durante un tiempo mayor que el legal, es un medio sutil de destruir la fortaleza del hombre al que se ha privado arbitrariamente de libertad, y de llevarle a la pérdida de identidad y la locura:

Unos muros que le robaban todo horizonte, unas preguntas sin respuesta, una acusación que no conocía, una incomunicación que era un desamparo sin límites, un suelo movedizo donde se iban hundiendo uno a uno sus atributos de ser libre, una boveda de anonimato que, día a día, bajaba más amenazadora sobre su cabeza ...19

Preguntas sin respuesta, incomunicación ... que más allá de la anécdota específica del protagonista alcanzan al hombre puertorriqueño del siglo XX, cubriéndolo con esa simbólica bóveda de anonimato que le impedirá perfilar su identidad. Y todo por un crimen oculto: querer ser puertorriqueño. Si en el adulto es algo implícito, en el niño protagonista de la escena colegial es una voluntaria aunque intuitiva toma de postura para defender lo propio. Por eso debe rebelarse ante la colonización intelectual que se inicia en la escuela, porque ésta refleja una realidad reiteradamente denunciada por Marqués en sus ensayos: el idioma extranjero y el progresivo desconocimiento de la propia historia constituyen un grave problema para afirmar la tradicional identidad puertorriqueña. En el cuento está bien subrayado por el hecho de que sólo un niño se rebela contra el sistema; mientras que "el puertorriqueño promedio demuestra tanta ignorancia y tanta indiferencia e insensibilidad respecto a su propio pasado, historia y tradición, hasta el extremo de aparecer (...) como careciendo totalmente de conciencia histórica" ${ }^{20}$ La imposición del inglés habría contribuido a ello ya que "atacar el idioma de un pueblo es (...) atacar en la raíz misma su personalidad, su más entrañable expresión espiritual, la esencia misma de su ser" ${ }^{21}$ Por eso Marqués abordará de nuevo el problema en una ambiciosa ojeada panorámica dentro de su polémico texto: "El puertorriqueño dócil (literatura y realidad psicológica) ${ }^{n}$-premio de ensayo del Ateneo Puertorriqueño en 1960 - considerando "la imposición y aceptación social del inglés en Puerto Rico, sin riesgo de error, como una manifestación psicológica más de la docilidad puertorriqueñan.$^{22}$

${ }^{19}$ René Marqués, "El juramento ...". Cahiers, 95-96.

${ }^{20}$ Marqués, "El ruido y la furia de los críticos del señor Kazin" (en El puertorriqueño dócil ..., Cahiers, 126).

${ }_{21}$ Marqués, "Las tres vertientes del problema del idioma". El puertorriqueño dócil ... Cahiers, 146. Este ensayo de 1963 insiste en un asunto ya planteado en "Idioma, política y pedagogía". El Mundo (San Juan de Puerto Rico, 16 de agosto 1960), y "El puertorriqueño dócil (literatura y realidad psicologica)" del mismo año.

${ }_{28}$ Marqués, El puertorriqueño docil ...,Cahiers, 188. 
Un asunto político alcanza así dimensiones antropológicas; los "puertorriqueños son hoy dóciles, sencillamente, porque han sido desde los comienzos de su historia un pueblo colonial". ${ }^{23}$ No obstante, "un sistema de instrucción pública virilmente anticolonialista podría, en dos o tres generaciones, cambiar en buena medida el cuadro psicosocial de la docilidad puertorriqueña" ${ }^{24}$ Una tesis muy simple y por ello bastante controvertida. Es obvio que la pervivencia del estatuto colonial a lo largo del XIX y la peculiaridad de E.L.A. en nuestros días han contribuido a perfilar la identidad de la Isla reflejándose en una toma de pastura de sus literatos. ${ }^{25}$ Aún así, sin respaldar por completo la afirmación de que se debe descartar ... "la teoría de que un régimen colonial sea capaz, por su propia fuerza, de destruir la personalidad de un pueblo de cultura sólidamente establecidan, ${ }^{26}$ el problema era, en efecto, que en 1898 la identidad puertorriqueña en aboluto quedaba asumida a nivel de conciencia colectiva ${ }^{27}$ En los intelectuales más lúcidos, como Eugenio $\mathrm{M}^{\mathrm{a}}$ de Hostos, era un ilusionado proyecto ligado al deseo de independencia. Curiosamente coexiste y se superpone a la visión de la Isla como realidad enferma y desvalida, habitual en los escritores finiseculares de cuño naturalista -Zeno Gandía, por ejemploy común al resto de Hispanoamérica. ${ }^{28}$

Locierto es que laindagación teórica del ser nacional, "el problema de lo que significa ser puertorriqueño, de lo que constituye la puertorriqueñidad ${ }^{29}$ es posterior, corresponde a la generación del treinta y a sus portavoces: Pedreira,

${ }^{29}$ Marqués, El ruido y la furia ..., Cahiers, 123.

${ }^{24}$ Marqués, El puertorriqueño dócil ..., Cahiers, 182, nota 46.

${ }^{25}$ He tocado el tema en mi artículo: "Literatura y liberación en Puerto Rico: la generacion del cuarenta" Cruz Anzata 9. Ensayos. Universidad Central de Bayamón, 1986) 119-146. 26 Vicente Géigel Polanco, El despertar de un pueblo (citado por Hilda Quintana; Maria Cristina Rodríguez y Gladys Vila Barnes, Personalidad y literatura puertorriqueñas (Madrid, Playor, 1985) 334.

${ }^{27}$ El mismo Géigel Polanco avala este aserto: frente a la minoría rectora "consciente de sus responsabilidades y ávida de servir los mejores intereses del país (...) [no habrá] un pueblo solidarizado en generosos ideales de vida y plenamente consciente de su fuerza" (Personalidad y literatura) 336. En nuestros dfas un escritor marxista como José Luis González ha partido de esta observación tiñéndola con el dialéctico enfrentamiento de clases: hacendados y profesionales, frente al pueblo bajo en una

nación en formación (que) estaba tan escindida racial, social, económica y culturalmente que más bien deberiamos hablar de dos naciones. O más exactamente, tal vez, de dos formaciones nacionales que no habfan tenido tiempo de fundirse en una verdadera sintesis nacional.

El pats de cuatro pisos y otros ensayos (Río Piedras: Huracán, 1982) 25.

28 Esta tesis determinista, que considera nefasto el mestizaje americano por propiciar la decadencia biológico-moral de la raza, gozó de acérrimos defensores, entre los que se destacan Bunge y Alcides Arguedas.

${ }^{29}$ Manuel Maldonado Denis, "La temática social en la literatura puertorriqueña". La Torre 42 (San Juan de Puerto Rico, abril-junio 1963) 193. 
Tomás Blanco y la Revista de las Antillas. Al plantear ¿qué somos? ¿cómo somos? parten de la discontinuidad evolutiva que signa la historia de Puerto Rico para volver a las raíces: la tierra, el hombre y la cultura hispánica. Aunque la situación peculiar respecto de los Estados Unidos es un factor no desdeñable en este enfoque, al examinar la cuestión proyectándola en el ámbito hispanoamericano, se puede observar la similitud de planteamientos. Efectivamente, la década del treinta corresponde a ese momento de inflexión vanguardista que Jean Franco ha denominado con acierto "la vuelta a las raíces" ${ }^{30}$ En este sentido puede establecerse un curioso paralelismo entre el jíbaro - personaje que desde Pedreira simboliza lo autóctono- y el gaucho argentino. Ambos son hombres a caballo que se mitifican por su conexión con la tierra y se erigen en símbolos de una cultura agraria destinada a desaparecer rápidamente como tal; son anacrónicos desde su misma génesis literaria, como lo prueba la novela arquetípica de Ricardo Güiraldes, Don Segundo Sombra. Se eligen porque representan las "esencias" nacionales frente a la desbordada inmigración que amenaza con desvirtuar Argentina, o a los cambios transculturales en la Isla .... El tema es importante en sí mismo porque caracteriza toda una etapa social y literaria del Nuevo Mundo. Pero además importa a nuestro trabajo porque este planteamiento pervive, aunque algo modificado, en la generación del cincuenta y René Marqués.

\section{LA DESQUICIADA EPOPEYA DEL HOMBRE CONTEMPORÁNEO}

En "El juramento" se insinúa brevemente el paso del campo a la ciudad provinciana que deslumbra y asusta a la vez al niño que fue el protagonista. No obstante, esa contraposición campo/ciudad ya se había marcado muy netamente en "Otro día nuestro", uno de sus primeros relatos .... En la mayoría de ellos los personajes que habitan en una ciudad rememoran con nostalgia su infancia campesina, enfrentándola al ámbito hostil que rodea su vida de adultos. Hasta tal punto es así que José Luis González ha caracterizado su obra como ... "la conmovedora búsqueda de un tiempo perdido, irrecuperable en definitiva por medio de la nostalgia militante". ${ }^{31}$ Ya su novela inicial, La víspera del hombre

so Jean Franco. La cultura moderna en América Latina (México, Joaquín Mortiz, 1971) 115-143. Lo que sucede es que esta "vuelta a la tierra" en Marqués se convierte en programa "patriológico - según Luis Rafael Sánchez-que informa y cohesiona todas sus actividades literarias con "el viaje trágico hacia el pasado, viaje empeñado en el rescate de una utopía perdida o quebrada por la llegada de los bárbaros ..." Luis Rafael Sánchez, "Las divinas palabras de René Marqués" Sin Nombre 10 (San Juan, oct-nov, 1979) 12. Aunque ya es sabido, tampoco conviene olvidar que la búsqueda de identidad en Hispanoamérica comenzará en ensayos como Radiografía de la pampa, de Ezequiel Martínez Estrada, y continuarḱ en décadas siguientes trasvasándose también a la novela. ${ }^{91}$ José Luis González. Literatura e identidad ..., 62 . González va mucho más allá al acusar a su amigo con notoria incomprensión: "René Marques, por su parte, se ha vuelto cada vez 
(1959) contempla el derrumbamiento del enclave cafetalero señoril, trasunto de la hacienda de los abuelos. El protagonista irá dejando atrás paralelamente el paraíso agrario y el de la niñez.

En resumen, idealización de la tierra como herencia de la inflexión vanguardista y

utopia de la sociedad precapitalista que en la obra de Marqués -como en gran parte de la larga tradicion costumbrista - se opone a la vulgaridad de la sociedad capitalista, al poder destructor de la máquina, al materialismo. ${ }^{32}$

Laindustrialización rápida, forzaday desigual, y el consiguienteincremento demográfico de las gran des ciudades son fenómenos sociológicos que configurarán Hispanoamérica durante la primera mitad del siglo XX..$^{33}$ En el plano literario tendrán su correlato en la proliferación de la narrativa urbana que "tiene por fuerza que acentuar el desarrollo psicológico. Son ahora los pensamientos, el estado de ánimo de los protagonistas, lo que lleva el peso de la acción". ${ }^{34}$

Como escritor moderno, Marqués elige la ciudad por centro; de forma casi siempre explícita, San Juan de Puerto Rico es esa "ciudad situada en América" ${ }^{25}$ en la que se desenvuelve la vida rutinaria y anodina de sus antihéroes. Evidentemente el protagonista de "El juramento" lo es, tanto por su anonimato y por el trabajo que desempeña:

Al taller de la imprenta no pudo ni siquiera mandar aviso. Pero el jefe del taller se habría enterado por los perídicos. Y en su puesto ya tendrían a otro esclavo de la maquina de linotipo.96

como por su actitud pasiva, falta de interés por un proceso político en que se juega la propia libertad. ¿Se debe al impulso autodestructor que según la tesis del mismo Marqués, definiría al puertorriqueño actual ${ }^{37}$ ¿O más bien

más conservador en su ideología. Él también se da cuenta de nuestros males, pero en vez de mirar hacia el futuro se refugia en un pasado idealizado". Palabras de José Luis González en la entrevista ya citada de Nora Orthmann y Caridad L. Silva de Velázquez, 34.

${ }^{32}$ Arcadio Dlaz Quiñones, "Los desastres de la guerra: para leer a René Manqués". Sin Nombre 10 (oct.-dic., 1979) 41.

${ }^{39} \mathrm{La} \mathrm{bibliografia} \mathrm{sobre} \mathrm{el} \mathrm{tema} \mathrm{es} \mathrm{exhaustiva.} \mathrm{Para} \mathrm{el} \mathrm{entorno} \mathrm{puertorriqueño} \mathrm{sigue} \mathrm{siendo}$ clásico el libro de Maldonado Denís, Puerto Rico: una interpretación ... ya citado.

${ }^{34}$ Betty Rita Gómez Lance. ¿Existe una "Promoción del Cuarenta"? En Revista Iberoamericana 58 (jul-dic 1964) 285.

${ }^{35}$ René Portico de Marqués, En una ciudad llamada San Juan, Casa de las Américas, 1962. La ciudad como prisión es eje de bastantes relatos, cuestión ya señalada por la crítica. Véase Luis Rafael Sánchez, Las divinas palabras ..., 18.

${ }^{36}$ René Marqués, "El juramento ...". Cahiers, 95.

${ }^{77}$ René Marqués, El puertorriqueño dócil ..., Cahiers, 161-169. 
transparenta la vigencia del absurdo que rige la vida de los individuos hoy? ${ }^{38} \mathrm{Tal}$ vez por ello el anónimo protagonista que los representa no lucha, convencido de ... Ta predestinación del hombre y (...) su subyugación a una fuerza superior que dirige su vida toda ..." ${ }^{39}$ Vistas así las cosas, la injusticia que supone una persecución política soterrada del pueblo puertorriqueño no es más que una faceta del absurdo existencial; ya que "un titiritero desconocido y burlón determina el curso que ha de seguir la vida del hombre desde el momento en que éste nace hasta el momento en que entra en la eternidad ..." ${ }^{40}$ Hay tres niveles, pues, en estas consideraciones: en los dos primeros -lo rutinario y lo políticounos hombres dominan a otros; pero en el tercero -el sentido úl timo de la vidason todos ellos mero juguete de fuerzas ignotas y trascendentes.

Uno de los aciertos de Marqués en este relato consiste en la voluntaria huida del patetismo. Ante los hechos distorsionados, el sentido del absurdo inmoviliza la tragedia al desrealizar las situaciones y proyectarlas en el plano de lo cómico. Hay dos referencias al respecto que enmarcan estructuralmente lo narrado, desde los preparativos del juicio:

Entonces comenzó el disparate. Emergí del estupor purgado de todo sentido de lo trágico. Y afloró a su conciencia el puro sentido del absurdo. Y con él, la risa. ${ }^{11}$

hasta que éste se cierra con una sentencia de culpabilidad incomprensible para el inocente protagonista:

Ya no sonreía. La sala y los seres que le rodeaban habían perdido de súbito el carácter absurdo que habían tenido hasta entonces (...) Y sintió la terrible congoja de recobrar conciencia de todo lo que es trágico y cotidiano. ${ }^{2}$

Entre ambos parámetros se desarrolla una entretenida parodia en términos de carnaval.

\section{LA RETÓRICA DE LO CARNAVALESCO}

La parodia se apoya en el enfoque irónico de acontecimientos cuyo nudo se escamotea al lector; es el verdadero "dato escondido" del texto:

\footnotetext{
${ }^{36}$ "Marqués nunca ha superado su formación existencialista. Sus lecturas de Heidegger, de Unamuno, del joven Sartre, lo llevan a crear personajes que terminan negando toda salida y regodeándose en un masoquismo existencial que hace infructuosa toda acción". Efraín Barradas, "El machismo existencialista de René Marqués. Relecturas y nuevas lecturas", Sin Nombre 3 (San Juan de Puerto Rico, oct-dic 1977) 73.

39 Betty Rita Gómez Lance, "Los cuentos de René Marqués". El Salvador, Revista La Universidad 90 (mar-abr, 1965) 103.

${ }^{40}$ Revista La Universidad, 103.

41 René Marqués, "El juramento ..." Cahiers, 96.

12 Cahiers, 109.
} 
Por lo menos una cosa estaba clara: este proceso revestía carácter inusitado. En él se estrenaba un crimen nuevo, reluciente, recién inventado (...)

Ya tenía, pues, otro eslabón de la cadena. Él era eso pero por asociación (...) En eso precisamente consistía el crimen recién inventado: en ser criminal siendo inocente (...) si a pesar de ser inocente era criminal, ni dudar que era culpable. Al menos ahora la cosa iba teniendo logica. ${ }^{43}$

Ironía, pues, como "procedimiento normal para exponer la comedia de las pretensiones humanas" ${ }^{44} \mathrm{E}$ ironía combinada con la técnica fundamental del satírico que es la reducción, es decir, "la degradación o desvalorización de la víctima mediante el rebajamiento de su estatura y dignidad". ${ }^{45}$ En el texto marquesiano se renuncia al liliputismo de los Viajes de Gulliver y se opta más bien por el despojamiento de la categoria personal ... "para poner al descubierto la corrompida desnudez que hay debajo".46 En consecuencia, a los ojos del protagonista el jurado se convierte en un pequeño zoo: el presidente es un "hombre-gato" (93, 99 y 102); el fiscal tiene cara de "perro inglés" (94, 99, 100 y 101) con "quijadas caninas" (95); "los jurados tenían caras de monos encerrados en un corral de madera, excepto el presidente que tenía cara de mangosta" (98).

Marqués lleva la ironía más lejos: aún reducidos a la pura animalidad los jurados sirven a la justicia con ... "honrada convicción" y llegan a creer "con entera sinceridad que él había jurado" (101), es decir, que es culpable. El texto escapa así al fácil maniqueŕsmo, que hubiera sido desafortunado. Este acierto se complementa con la utilización del diminutivo, que si bien contribuye al efecto reductor, no deja de tener un matiz entre afectivo e irónico. ${ }^{47}$

Dentro de la historia conviene destacar la eficacia corrosiva de la risa. La risa es el único elemento desestabilizador que se permite el protagonista desde su perpleja pasividad .... La incomprensión, el estupor, estallan en franca carcajada o leve sonrisa que amenaza el equilibrio del fiscal:

Lograron al fin curarle la risa de la boca. Pero no de los ojos. Y esa, que nadie podía quitarle, fue su mayor placer durante el resto del proceso. La risa de sus ojos no interrumpia al tribunal (...). Nadie la veía. Excepto el fiscal (...) Y esa risa lo desconcert6, lo obsesion 6 , lo enloqueci6. ${ }^{45}$

El humor es arma letal, la única contra las injusticias del sistema. En la narrativa contemporánea ha sustituido con ventaja a la vieja denuncia de tono

4s Cahiers, 99.

"Mattew Hodgart, La satira (Madrid: Guadarrama,1969) 131.

${ }^{45}$ La satira, 115.

4s La sátira, 128.

${ }^{47}$ Monita, el martillito, la maquinita, el corralito, todos bañaditos ... se reiteran en este sentido.

4s René Marqués, "El juramento ...", Cahiers, 95. 
panfletario, como se desprendía de la cita de Donald Shaw que recogi antes. Risa, a nivel de historia; ironía a nivel de discurso que procede de la falta de lógica interna en los acontecimientos narrados y del conflicto de creencias entre lo expuesto por el narrador y lo que intuimos del autor. ${ }^{49}$ Por la biografía de Marqués sabemos de su lucha en favor de la independencia de Puerto Rico, de su atracción irracional por la inviable gesta nacionalista .... Pues bien, el narrador es todo lo contrario, un narrador ajeno a la historia -extraheterodiegético según la citada terminología de Genette-que no abandona su papel rector del relato perojamás se inmiscuye sentimentalmente en él. A pesar de ello, a la hora de revivir situaciones pretéritas el foco del narrador se centra en la mente del personaje, en un tipo especial de focalización interna que no es, por supuesto, verdadero monólogo interior.

Modernidad técnica ... planteamiento intertextual con la problemática de la identidad puertorriqueña al fondo, y en ella la antiheroica epopeya de un hombre que se mueve desde la incomprensión al absurdo .... Epopeya rutinaria, tal vez no tan desesperanzada como la de los hombres de Onetti, pero trágica porque es la gesta de todos y cada uno de los seres humanos en la sociedad actual .... Entre bastidores, un narrador que carnavaliza la historia distorsionándola para huir del efectismo patético .... Por todo ello, "El juramento" es, a mi entender, uno de los cuentos más modernos y mejor logrados de su autor. Con él y con algunosotros textos Marqués se adelanta a lageneración del setenta, cuyos novelistas "comparten una seria preocupación por la realidad puertorriqueña". Todos profundizan en los problemas que denunciara la "Generación del 50 ". Pero no son meros epígonos nuestros porque han ampliado considerablemente la temática de la narrativa puertorriqueña", ${ }^{50}$ a la vez que alcanzan la "ruptura del discurso literario en la línea de "corromper el texto tradicional". ${ }^{.1}$

\footnotetext{
${ }^{49}$ Ver al respecto las pistas al lector para descubrir la ironía segun Wayne Booth, Retórica de la ironfa (Madrid, Taurus, 1986) 90-289.

so José Luis González, entrevista ya citada, 35.

${ }^{51}$ Luis Rafael Sánchez, entrevista realizada por Helen Calaf de Aguera y aparecida en Hispamérica 23-24 (1979) 77.
} 